\title{
Will Ellsworth-Jones, We Will Not Fight...The Untold Story of World War One's Conscientious Objectors
}

Jean-Louis Legalery

\section{OpenEdition}

Journals

Édition électronique

URL : http://journals.openedition.org/rfcb/317

DOI : $10.4000 / \mathrm{rfcb} .317$

ISSN : 2429-4373

Éditeur

CRECIB - Centre de recherche et d'études en civilisation britannique

Édition imprimée

Date de publication : 15 janvier 2015

ISSN : 0248-9015

Référence électronique

Jean-Louis Legalery, «Will Ellsworth-Jones, We Will Not Fight...The Untold Story of World War One's Conscientious Objectors », Revue Française de Civilisation Britannique [En ligne], XX-1 | 2015, mis en ligne le 01 mai 2015, consulté le 22 septembre 2020. URL : http://journals.openedition.org/rfcb/317 ; DOI : https://doi.org/10.4000/rfcb.317

Ce document a été généré automatiquement le 22 septembre 2020.

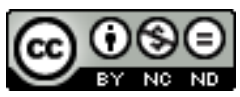

Revue française de civilisation britannique est mis à disposition selon les termes de la licence Creative Commons Attribution - Pas d'Utilisation Commerciale - Pas de Modification 4.0 International. 


\title{
Will Ellsworth-Jones, We Will Not Fight...The Untold Story of World War One's Conscientious Objectors
}

\author{
Jean-Louis Legalery
}

\section{RÉFÉRENCE}

Will Ellsworth-Jones, We Will Not Fight...The Untold Story of World War One's

Conscientious Objectors, Aurum : London, 2009.

1 L'auteur, Wills Ellsworth-Jones, est journaliste. Il vit à Londres et a travaillé successivement pour The Sunday Times, pour lequel il a été correspondant à New York, The Daily Telegraph et Saga Magazine. We Will Not Fight...The Untold Story of World War One's Conscientious Objectors est son premier ouvrage. Wills Ellsworth-Jones a écrit une chronique - non pas avec des personnages de fiction mais avec des individus ayant vraiment vécu ce cauchemar - qui démarre au milieu du mois de juin 1916, année de toutes les désillusions, du doute - cette guerre ne devait-elle pas, en 1914, être rapidement menée et gagnée ? - et de l'introduction de la conscription, et qui met en scène les quatre frères Brocklesby, au destin si différent et cependant commun dans la tragédie, depuis qu'ils ont dû quitter leur petit village natal de Conisbrough - où le quatrième, George, réformé, était resté comme recruteur - dans la région minière du South Yorkshire.

2 Harold, l'aîné, est déjà au front en France où il a été blessé, Philip, le second, vient d'être promu lieutenant et s'apprête à rejoindre son unité à Boulogne, où il espère voir leur plus jeune frère, Bert, emprisonné avec trente-quatre autres objecteurs de conscience. Il faut rappeler qu'en 1914 la Grande-Bretagne est un pays où il semble absolument inconcevable de ne pas vouloir combattre et où la conscription est superflue, puisque le nombre de volontaires dépasse les capacités d'accueil et d'organisation de l'armée. Mais deux ans plus tard, il y a 16.300 objecteurs de 
conscience, dont 6.000 sont emprisonnés, et un nombre croissant de jeunes hommes qui préféraient mourir face à un peloton d'exécution pour insubordination plutôt que d'aller combattre sur le continent. De fait le gouvernement de coalition de David Lloyd George fait voter la conscription.

3 Harold est parti le premier en 1914 dans une sorte d'euphorie aveugle et xénophobe. C'est l'époque où The Daily Mail incite ses lecteurs à refuser d'être servi, au restaurant, par un garçon allemand. L'épouse de D.H. Lawrence, Frieda, paiera ses origines allemandes au prix de nombre d'insultes dans la rue. Philip va suivre son destin avec discipline, mais sans conviction, à partir de 1915. Quant à Bert, il n'est pas un rebelle, il n'a jamais été impliqué dans quelque problème que ce soit. Il est simplement imprégné de religion et il s'en tient fermement au sixième commandement, Thou shalt not kill. Son choix est d'autant plus difficile que les ecclésiastiques, même les Quakers avec leur slogan Let us stand or fall together - soutiennent la guerre. Bert doit même endurer d'abord l'ignominie des white feathers, ce symbole présumé de la couardise que les jeunes femmes accrochent au veston des jeunes gens qui refusent d'aller combattre aux côtés des autres ; puis la honte de l'arrestation au domicile familial pour insoumission.

Il sera soumis à un interrogatoire surréaliste auquel il répondra avec dignité, cf pp106/107 :

-Why are you a conscientious objector?

-War is breaking the command 'Thou shalt not kill'

-Do you not think that those commands apply to individuals but not to the state?

-They apply to both.

Parallèlement à la résistance individuelle des COs se développe l'opposition collective à la guerre dans la société britannique, avec d'autant plus d'impact que des fils de parlementaires commencent à contester. Ces différentes prises de position vont sauver Bert, condamné à mort, sentence qui sera commuée finalement en dix ans d'emprisonnement. Harold et Philip ont été blessés, mais ont survécu à cette guerre. Bert a survécu, lui aussi, et a été de toutes les manifestations pacifistes et antimilitaristes jusqu'à la fin des années 1960 .

Wills Ellsworth-Jones n'est ni historien, ni spécialiste de la première guerre mondiale, mais son intérêt pour les objecteurs de conscience a été éveillé par un article publié en mai 1999 dans le Daily Telegraph sous le titre Castle cell graffiti of Somme pacifists brought to life, récit de seize objecteurs détenus à moitié nus dans les cellules de Richmond Castle, dont les murs étaient recouverts de dessins, de graffiti et de poèmes, avant d'être envoyés en France pour y être exécutés pour désertion. Son ouvrage est une photographie réussie d'une nation d'abord galvanisée par l'enthousiasme, puis minée par le doute.

\section{AUTEURS}

\section{JEAN-LOUIS LEGALERY}

Université de Besançon 